\title{
Does the Poor's Consumption of Calories Respond to Changes in Income? Evidence from Pakistan
}

\author{
FRANQUE GRIMARD
}

\begin{abstract}
This paper examines the relationship between income and calorie consumption for households in developing countries. Recent papers have questioned the strength of this relationship on the basis of several measurement problems that tend to overstate the responsiveness of calories consumption to income. The paper uses a household data set from Pakistan and estimates calories income elasticities for rural and urban households. The estimation takes into account the concerns raised by Behrman and Deolalikar (1987) and Bouis and Haddad (1992) about quality effects and unobservable variables. The paper finds that the elasticity is significantly different from zero. Furthermore, the relationship appears to be different according to households' incomes. Poor households' responsiveness of calories intake to changes in income is greater than that of the entire sample. These results are consistent with the conventional wisdom that existed before the recent criticisms.
\end{abstract}

\section{INTRODUCTION}

Despite considerable progress in recent decades, the goal of adequate food and nutrition for all is still elusive. ${ }^{1}$ Eradicating hunger and malnutrition is a high priority of aid agencies and governments throughout the world. Several policies have been enacted to fight malnutrition. One of them has focused on raising the incomes of the poorest people. Indeed, World Development Report 1981 expressed the view that

Malnutrition is largely a reflection of poverty: people do not have income for food. Given the slow income growth that is likely for the poorest people in the foreseeable future, large numbers will remain malnourished for decades to

Franque Grimard is Assistant Professor of Economics at McGill University, Montréal, Canada.

Author's Note: I have benefited from helpful comments, advice, and encouragement from Harold Alderman, Anne Case, Angus Deaton, John Galbraith, René Garcia, and Nadeem Ilahi. I also thank an anonymous referee for useful comments and suggestions. All remaining errors are mine. I am grateful to Fonds pour la Formation de Chercheurs et l'Aide à la Recherche (FCAR) for generous financial support.

${ }^{1}$ The World Health Organisation estimates that over 780 million people, mainly in Africa, South Asia, and Latin America, do not have enough food to meet their basic daily needs for energy and protein. More than two billion people subsist on diets that lack the essential vitamins and minerals required for normal growth and development and for the prevention of premature death and disabilities such as blindness and mental retardation. 
come... The most efficient long-term policies are those that raise the income of the poor.

The conventional wisdom proposed above is that income increases should allow individuals to increase their food intake and nutrient consumption, which in turn should improve their nutritional status. On the basis of this argument, billions of dollars of aid have been spent on programmes aimed at raising income of the poor with the justification that it would reduce malnutrition.

However, recent studies have cast doubts on this conventional thinking. Some studies have argued that the link between income and nutrient consumption is weak. Others have questioned the connection between food intake and nutritional status. Overall, these studies have challenged the relationship between income and nutrition and have undercut the basis of the funding of the programmes towards the poor. Whereas a study of the strength of the relationship between food intake and nutritional status is perhaps best left to nutrition specialists, economists may have something to say about the link between income and nutrient consumption. Indeed, recent studies suggest that the view proposed by WDR 1981 overstates the impact of income increases on nutrient intake. These studies find that the income elasticity of calories/nutrients is smaller than what was previously estimated and, in some cases, not significantly different from zero. Furthermore, they find little difference between the average elasticity and the elasticity for the poorest members of a community.

In an excellent review of the literature, Alderman (1993) discusses the recent econometric evidence on the link between income and the demand for calories. ${ }^{2}$ These studies have attacked the traditional view on elasticity on the grounds that it did not take into account several problems that affect the estimation of the incomecalories elasticity. The first problem is the measurement error. Bouis and Haddad (1992) point out that since accurate data on income are difficult to collect, total expenditure is often used as a proxy for permanent income. This causes a bias in measuring calorie elasticity, since errors in reported food acquisition and in total expenditures are correlated. ${ }^{3}$ The second potential source of upward bias is missing

${ }^{2}$ Most studies focus on calories as a proxy for all nutrients. Although it is recognised that nutrition is more than just calories, this is justified based on the opinion that energy is the limiting element in poor households' nutrition. It would appear that a satisfactory consumption of calories is correlated with an acceptable consumption of proteins. For a different opinion, see Graham and others (1981).

${ }^{3}$ The direction of the bias when using such a variable cannot always be determined from theory. For example, when the dependent variable is a measure of food expenditures, the bias of the coefficient of total expenditures comprises both the standard errors-in-variables bias toward zero and an upward bias due to positive correlation between measurement error in the dependent and independent variables. To solve this problem, Bouis and Haddad propose the use of an instrumental variable for expenditure, and in their study of a sample from the Philippines they find that the elasticity is reduced from 0.41 to 0.25 . 
variables. Behrman and Wolfe (1984) argue that higher income is often associated with higher energy consumption not only because one causes the other, but because both of them are associated with better schooling for women. ${ }^{4}$

Besides the omitted variable and errors-in-variables problems, Alderman (1993) points out that unobserved quality may be a more important source of bias. Indeed, studies by Bouis and Haddad (1992) and Behrman and Deolalikar (1987) show a marked difference between elasticity estimates using quantities imputed from food expenditures and those based on data provided by individuals on the food they consumed in the previous twenty-four hours. Two explanations have been offered to reconcile this difference. Bouis and Haddad explain that data on food expenditure often include purchases for guests and labourers. Since these purchases for nonfamily consumption are correlated with income, they would lead to an upward bias. Behrman and Deolalikar (1987) attribute the smaller elasticities from twenty-fourhour food recall data to a behavioural source. With rising income, households increase expenditure on food at a much faster rate than they increase the quantity purchased. This means that an increase in expenditure on rice would lead to an overestimate of the increase in calories from rice because the higher expenditure reflects in part the improved quality of rice purchased. ${ }^{5}$

If the "revisionist" studies are right and can be generalised to other poor communities, the justification for allocating aid funds for nutrition may be weak. At the very least, one should view these funds as income transfers per se without using any nutritional justification. Another point of view may suggest that these funds are misallocated and should be directed to other purposes. For instance, a weak link between income and nutrition would undercut some of the rationale for complementing macroeconomic adjustment programmes with measures aimed at protecting nutrient intake. Consequently, it is important to understand the arguments these studies present and use other data sets to see if the elasticity is not only lower than previously thought but also if the elasticity for the poorest members of the community is different from that of the community as a whole.

This paper discusses some of the recent criticisms and estimates the incomecalorie elasticity for households in Pakistan by using two different methods. ${ }^{6}$ It first

${ }^{4}$ One possible way to deal with the omitted variable bias is to use the community or fixed effects. Alderman (1986) and Bouis and Haddad (1992) estimate calories demand with household panel data and find that fixed effects have very little effect on income response.

${ }^{5}$ For some food categories, the quality effect can be important. For instance, Alderman (1986) presents evidence that more than half of total food expenditure elasticities may reflect such quality effects.

${ }^{6}$ Because of data and estimation concerns, this paper concentrates solely on the causal relationship from income to nutrition. There is also the possibility raised by the efficiency wage hypothesis which postulates that a better nutrition brings a higher wage to the individual worker. Some evidence on the importance of nutrition in determining labour productivity in developing agriculture is provided by Strauss (1986) for Sierra Leone and by Deolalikar (1988) for South India. 
focuses on Behrman and Deolalikar's point about the role of unobserved quality. It estimates calories elasticities for households residing in Pakistan in 1985 using data on food expenditure as well as on calories consumed, and presents a method to account for quality effects. The paper indeed finds that once the quality effect has been taken into account, the calories elasticities are reduced. However, contrary to Behrman and Deolalikar's results, the elasticities are still significantly different from zero and, furthermore, those obtained for the poorest members of the Pakistan data set used are greater than those estimated for the overall sample.

Secondly, the paper uses a reduced demand form for total calories to estimate the income calorie elasticity. Both estimation methods yield that the overall elasticity is significantly different from zero. Furthermore, the calorie-income relationship appears to be different according to households' incomes. Poor households' responsiveness of calories intake to changes in income is greater than that of the entire sample. These results are consistent with the "conventional wisdom" summarised above that has been criticised by some recent studies.

The structure of the paper is as follows. First, the data set used in the estimation will be discussed. Second, the elasticity will be estimated using the indirect method. Deaton and Grimard (1992) estimated the quantity expenditure elasticities for the same data set. It is relatively straightforward to convert these into calories elasticities. Third, the quality aspect will be addressed by calculating the expenditure-income elasticity of the average cost of nutrient in order to get a more accurate calorie-expenditure elasticity. The fourth step in the analysis is to directly estimate the demand for nutrients by estimating linear and non-linear reduced forms. Having found some elasticities using the two methods, one will then examine the remaining issues that any estimation of the calorie-expenditure relationship should address.

\section{THE DATA}

The data set is the Household Income and Expenditure Survey (HIES) which was carried out from July 1984 to June 1985 by the Federal Bureau of Statistics (FBS) of the Government of Pakistan. The HIES questionnaire surveyed households on their purchases over the previous month. These were recorded on a recall basis. As it is the case with most household surveys, the HIES recorded expenditures and quantities but did not collect any prices. 9119 rural households and 7461 urban households responded to a detailed questionnaire on expenses and sources of income. The households were surveyed approximately equally over the time-period the HIES was carried out.

Two categories of quantities are reported in the HIES. The first category encompasses the goods acquired through market exchanges, whereas the second refers to goods either given as gifts in kind or as home production. Unfortunately, 
interviewers did not weight the reported quantities. In return, since the HIES was interested particularly in examining the consumption of items rather than expenditures, interviewers were instructed to take into account bulk purchases that would not be consumed during the recall period of a month. Consequently, the reported quantity should reflect the household's consumption of food items over the last 30 days. For both categories, all the quantities of the individual food items that were available in the survey were converted into calories at the lowest possible level, using conversion factors from the Department of Agriculture of the Government of Pakistan. Particular care was taken to account for factors such as milling, bones, and peels that may influence the transformation of quantity reported into the calories intake.

Tables 1 and 2 present the budget and calorie shares for the full rural and urban sectors on a monthly basis by households, commodity groups, and expenditure decile. Table 1 reveals that rural households spend on average half of their monthly budget on food but, as expected, that food share diminishes as expenditure increases. Wheat, a basic foodstuff, sees its relative importance diminishing through expenditure decile, though the rice budget share rises slightly and then falls. Dairy products appear to be a normal good. In terms of calories, wheat is by far the principal source for all rural households, though its relative importance also diminishes through expenditure deciles. The rice calorie share follows the same pattern as the budget share: it rises slightly and then declines.

The food share represents 43.3 percent of the average urban household monthly budget. As in the rural sample, wheat, other foods, and dairy products comprise the major food expenditures, though the first two items' importance declines as expenditure rises. Wheat is the major source of calories for the urban sector with the other food having the same relative importance as in the rural sector. Both tables appear to support the taxation analysis carried out in Deaton and Grimard (1992), which suggested that, for equity and efficiency reasons, rice was a better candidate than wheat for a consumers' tax increase.

Calories are totalled for both samples and translated into daily calories consumption per household member. Table 3 shows the mean and standard deviations for the average daily calories consumption per capita by expenditure decile for the urban and rural sectors. The table was computed using all the observations available for the two samples. The first observation is that the urban average daily consumption is relatively low: the recommended daily allowance of calories for a reference Pakistani man with moderate activity is 2550 calories per day, which is considerably greater than the sample urban average. While the minimum calorific requirements vary with each individual, the human body does adapt to restrictive conditions and 2550 calories per day may consequently be a relatively high figure. 
Table 1

Budget and Calorie Shares, HIES 1984-85

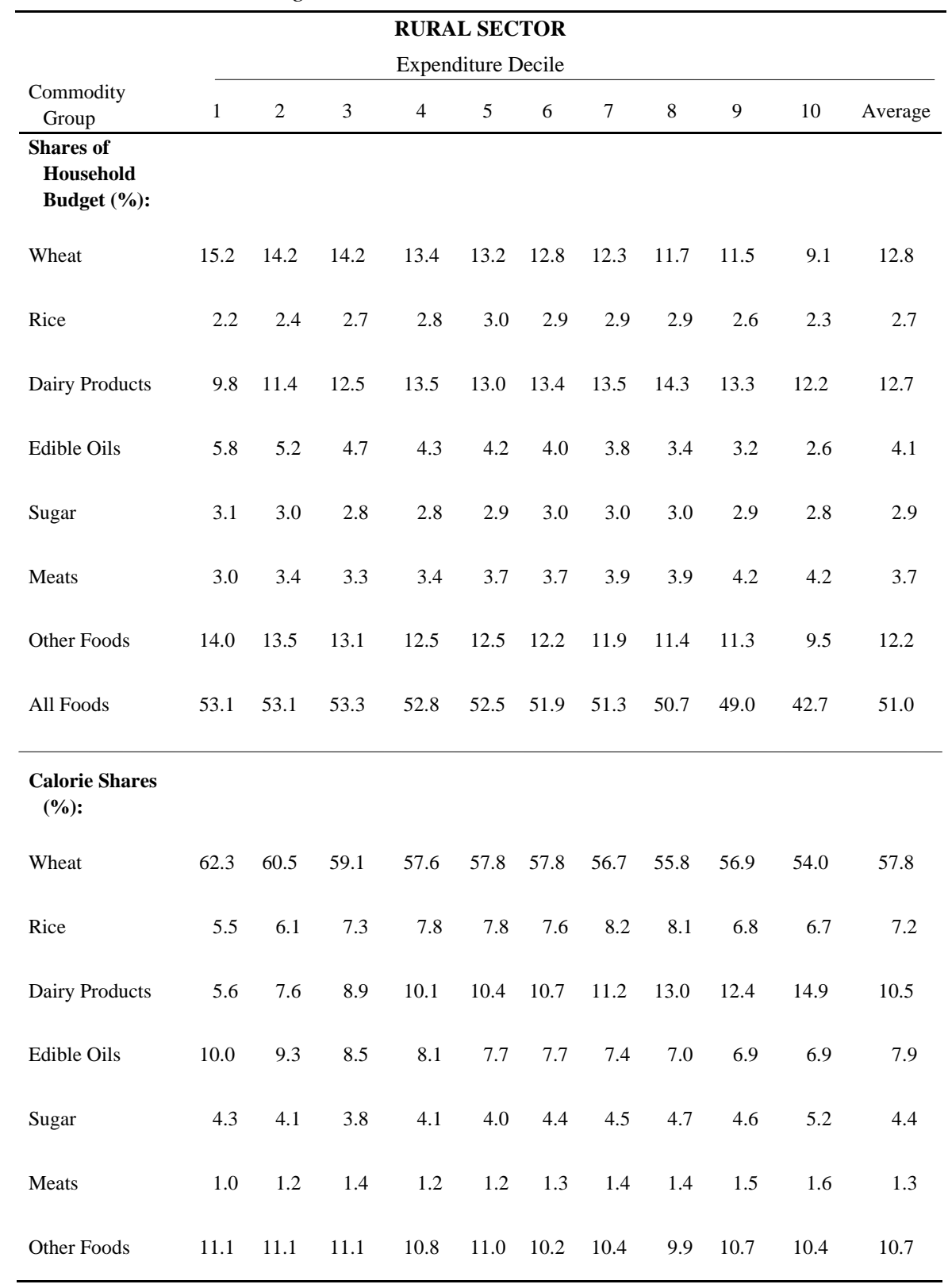


Table 2

Budget and Calorie Shares, HIES 1984-85

\begin{tabular}{|c|c|c|c|c|c|c|c|c|c|c|c|}
\hline \multirow[b]{3}{*}{$\begin{array}{l}\text { Commodity } \\
\text { Group }\end{array}$} & \multicolumn{10}{|c|}{ URBAN SECTOR } & \multirow[b]{3}{*}{ Average } \\
\hline & \multirow[b]{2}{*}{1} & \multirow[b]{2}{*}{2} & \multirow[b]{2}{*}{3} & \multicolumn{4}{|c|}{ Expenditure Decile } & \multirow[b]{2}{*}{8} & \multirow[b]{2}{*}{9} & \multirow[b]{2}{*}{10} & \\
\hline & & & & 4 & 5 & 6 & 7 & & & & \\
\hline $\begin{array}{l}\text { Shares of } \\
\text { Household } \\
\text { Budget (\%): }\end{array}$ & & & & & & & & & & & \\
\hline Wheat & 11.9 & 11.7 & 10.7 & 10.5 & 9.6 & 8.9 & 8.4 & 7.6 & 6.5 & 4.1 & 9.0 \\
\hline Rice & 1.7 & 1.9 & 2.0 & 2.1 & 2.1 & 2.4 & 2.1 & 1.9 & 1.8 & 1.4 & 1.9 \\
\hline Dairy Products & 9.2 & 9.4 & 9.9 & 10.2 & 9.8 & 9.8 & 9.9 & 9.8 & 9.6 & 7.5 & 9.5 \\
\hline Edible Oils & 5.5 & 5.2 & 4.9 & 4.7 & 4.5 & 4.4 & 4.2 & 4.0 & 4.5 & 2.4 & 4.3 \\
\hline Sugar & 3.3 & 3.3 & 3.4 & 3.3 & 3.2 & 3.2 & 3.1 & 2.8 & 2.5 & 1.7 & 2.9 \\
\hline Meats & 4.1 & 4.6 & 4.4 & 4.9 & 5.2 & 5.2 & 5.4 & 6.0 & 6.1 & 6.2 & 5.2 \\
\hline Other Foods & 11.7 & 11.7 & 10.8 & 10.9 & 10.6 & 10.4 & 10.1 & 9.6 & 9.1 & 7.4 & 10.2 \\
\hline All Foods & 47.5 & 47.9 & 46.3 & 46.9 & 45.3 & 44.2 & 43.2 & 41.7 & 39.2 & 30.8 & 43.3 \\
\hline $\begin{array}{l}\text { Calorie Shares } \\
\text { (\%): }\end{array}$ & & & & & & & & & & & \\
\hline Wheat & 57.9 & 57.6 & 56.9 & 56.3 & 54.8 & 53.4 & 52.6 & 52.1 & 51.0 & 46.0 & 53.9 \\
\hline Rice & 5.0 & 5.8 & 6.1 & 6.3 & 7.4 & 7.1 & 7.2 & 7.0 & 6.8 & 7.1 & 6.6 \\
\hline Dairy Products & 5.4 & 5.5 & 6.1 & 6.4 & 6.2 & 6.6 & 7.3 & 7.7 & 8.5 & 10.8 & 7.1 \\
\hline Edible Oils & 12.3 & 12.2 & 12.0 & 12.0 & 12.4 & 13.1 & 12.7 & 13.3 & 13.2 & 13.6 & 12.7 \\
\hline Sugar & 6.7 & 6.2 & 6.4 & 6.3 & 6.3 & 6.9 & 7.4 & 7.0 & 6.7 & 6.8 & 6.7 \\
\hline Meats & 1.8 & 2.0 & 2.0 & 2.3 & 2.4 & 2.7 & 2.7 & 3.1 & 3.4 & 4.3 & 2.7 \\
\hline Other Foods & 10.8 & 10.6 & 10.4 & 10.2 & 10.4 & 10.2 & 10.0 & 9.7 & 10.3 & 11.3 & 10.4 \\
\hline
\end{tabular}


Table 3

Average Daily Consumption Per Capita by Expenditure Decile

\begin{tabular}{cccccc}
\hline & \multicolumn{2}{c}{ Urban Sector } & & \multicolumn{2}{c}{ Rural Sector } \\
\cline { 5 - 6 } Expenditure Decile & Mean & $\begin{array}{c}\text { Standard } \\
\text { Deviation }\end{array}$ & & Mean & $\begin{array}{c}\text { Standard } \\
\text { Deviation }\end{array}$ \\
\hline 1 & 1878 & 1041 & 2176 & 983 \\
2 & 1971 & 2338 & & 2191 & 856 \\
3 & 2185 & 3270 & & 2272 & 854 \\
4 & 1963 & 788 & 2295 & 907 \\
5 & 1978 & 877 & 2293 & 793 \\
6 & 2153 & 3625 & 2389 & 855 \\
7 & 2062 & 2136 & 2410 & 758 \\
8 & 2136 & 771 & 2557 & 1042 \\
9 & 2261 & 794 & & 2631 & 1023 \\
10 & 2633 & 1160 & 3219 & 1906 \\
Average & 2122 & 1889 & 2443 & 1086 \\
\hline
\end{tabular}

Nevertheless, it is still surprising to see a relatively low average since the FBS tries to oversample rich households in urban sectors. This may be caused by some underestimation of calories due to the fact that calories consumed outside the house are not recorded. For instance, there are some households that record no calorie consumption at all but nevertheless have expenditures on other items. Urban households are more likely to eat outside the house and the data does not account for that, though one can find out if the given household has purchased food outside the house and, by comparing the relative budget shares of food purchased for consumption in the house and shares of dining out, one can have an idea of the relative frequency. One additional difficulty is that meals given to servants and guests are not properly taken into account by the questionnaire. This problem, pointed out by Bouis and Hadded, may bias the estimation of calories elasticity upward, since higher income is correlated with more servants, which would increase the total amount of calories consumed. ${ }^{7}$ Other potential problems include the possibility that interviewers may have recorded bulk purchases despite FBS instructions. Hence, accounting for the effects of dining out, meals to servants and bulk purchases is a priori ambiguous.

The relatively high means and standard deviations for some urban deciles $(2,3,6,7)$ suggest that the data set has some outliers which may or may not be legitimate. Greater attention should perhaps be devoted to the removal of outliers in both rural and urban data sets. Yet this may remove observations that are legitimately

${ }^{7}$ One could try to account for this using a similar method to that of Deaton and Subramanian (1994), who regress total calories on the number of meals given to guests and servants in order to adjust available calories. Unfortunately, the present data set does not allow for this possibility. 
low or high. Consequently, all the computations will be done using the full sample (except when done in logs), though one should be aware that the results, particularly the urban ones, may be sensitive to the data. ${ }^{8}$ To mitigate the influence of outliers, the estimation will also be done using the so-called "robust" regressions methods that reduce the influence of large residuals. It is left to the reader to judge as to which results encourage more confidence.

\section{ESTIMATING THE ELASTICITY}

The income-calorie debate originated with a series of articles by Behrman and associates [Behrman and Wolfe (1984); Behrman and Deolalikar (1987)]. Behrman and Deolalikar (1987) synthesise the argument: they point out that the purchase and consumption of food serve many purposes in addition of the provision of nutrients. Foods providing equal quantities of nutrients may differ in tastes, appearances, social status, odour, degree of processing, etc. Hence a constant one-to-one relationship between food purchases and nutrient intake does not necessarily exist. For instance, it is quite possible that a high food-income elasticity is consistent with low nutrient income elasticity because, even at a low household income level, there would be a strong demand for tasty and palatable foodstuffs as opposed to calories per se.

The problem would appear to be empirical: how to properly measure the nutrients' responsiveness to changes in income. A first difficulty is that income is often badly measured and, consequently, is not considered to be a good approximation for permanent income. Most estimation procedures deal with this problem by substituting total expenditure for income because it is considered that expenditure is better measured and is a better reflection of life-time resources. Using total expenditure as a proxy for permanent income, the literature offers two methods of measurement of the income elasticity of nutrients/calories: the indirect and the direct approaches. The direct method first converts quantities of all groups of food consumed into calories using a nutritional table. For instance, one adds calories obtained from consuming meat products to those from cereals, and so on. One then estimates the calorie-expenditure elasticity from a reduced from demand for calories. The indirect method reverses the order of estimation. First, one finds food group expenditure elasticities by estimating a food expenditure system. The resulting group

${ }^{8}$ For instance, Ercelawn (1990), in a calories-based poverty study using the same 84-85 HIES data set, removed 1181 of the 16580 total observations and found the following averages: 2574 for the rural sector and 2354 for the urban sector. Though the averages are higher, the relative order of magnitude remains the same: urban values are still lower than the rural ones. Perhaps the low urban average is not an artifact of the quality of the data. Table 4 shows a very preliminary selection of data where zero calories values (70 obs.) and very high per capita values (>7000, i.e., 23 obs.) are removed in the initial urban data set. The calorie consumption per capita appears better behaved across deciles but shows an even lower average value. Given that these extreme values may in fact be legitimate, this analysis will perform the estimation with the full available data. 
Table 4

Average Daily Consumption Per Capita by Expenditure Decile with Extreme Values Removed

\begin{tabular}{ccc}
\hline & \multicolumn{2}{c}{ Urban Sector } \\
\cline { 2 - 3 } Expenditure Decile & Mean & Standard Deviation \\
\hline 1 & 1947 & 924 \\
2 & 1918 & 759 \\
3 & 1987 & 777 \\
4 & 1984 & 765 \\
5 & 1977 & 683 \\
6 & 2004 & 756 \\
7 & 2036 & 752 \\
8 & 2132 & 740 \\
9 & 2253 & 762 \\
10 & 2558 & 936 \\
Average & 2080 & 809 \\
\hline
\end{tabular}

elasticities, i.e., that of meat, cereals, etc., on are then additively transformed into total calories expenditure elasticity by using conversion factors that depend on the relative importance of each food group in terms of total calories. Theoretically, both methods should yield the same calorie-expenditure elasticity.

To see this, let us define total nutrients consumed of a particular type (e.g., calories)

$$
\begin{array}{llllllll}
n=\sum_{i} k_{i} f_{i} & \ldots & \ldots & \ldots & \ldots & \ldots & \ldots
\end{array}
$$

where $n$ is the quantity of calories consumed, $k_{i}$ is the average calories content of a unit of food group $i$, and $f_{i}$ is the number of units consumed of food group $i$. The total expenditure elasticity for calories can be found by differentiating the above:

$$
\eta_{n E}=\sum_{i} \theta_{i} \eta_{f_{i} E}+\sum_{i} \theta_{i} \eta_{k_{i} E} \quad \ldots \quad \ldots . \quad \ldots
$$

where $\eta_{x E}$ is the elasticity of any $X$ with respect to $E$, total expenditure, and $\theta_{i}$ is the share of the total calories consumed obtained from food group $i$.

Now, let us note that expenditure on the $i$ th food group is $E_{i}=p_{i} f_{i}$. Consequently, the expenditure elasticity of food demand for the $i$ th food group is

$$
\eta_{f_{i} E}=\eta_{E_{i} E}-\eta_{p_{i} E} \quad \ldots \quad \ldots \quad \ldots \quad \ldots
$$

where $p_{i}$ is the unit price of the ith food group. Let us substitute Equation (3) into Equation (2) in order to have an expression in terms of calories:

$$
\eta_{n E}=\sum_{i} \theta_{i} \eta_{E_{i} E}-\sum_{i} \theta_{i} \eta_{p_{i} E}+\sum_{i} \theta_{i} \eta_{k_{i} E} \quad \ldots \quad \ldots
$$


Unfortunately, household surveys seldom provide the unit price, $p_{i}$, of the $i$ th food group chosen by the household. However, since expenditure and quantities of the food item(s) are available from the surveys, one can use the ratio $p_{i} / k_{i}=q_{i}$ where $q_{i}$ is the average cost of the calories obtained from food group $i$. Consequently, Equation (4) can be rewritten as

$$
\eta_{n} E=\sum_{i} \theta_{i} \eta_{E_{i} E}-\sum_{i} \theta_{i} \eta_{q_{i} E} \quad \ldots \quad \ldots \quad \ldots .
$$

Equation (5) states that the calories elasticity is a weighted sum of the total expenditure elasticity of expenditure on the group of goods minus a weighted sum of how the average cost of calories for each group varies with total outlay. Thus, to the extent that consumers, as they grow richer, substitute expensive non-nutrient characteristics for nutrients within the group, $\eta_{q_{i} E}$ will be large and the overall expenditure elasticity of calories will be reduced. Both estimation procedures described above effectively assume that second right-side term in Equation (5) is zero, that is, that the elasticity of the average cost of nutrient with respect to income/expenditure is zero.

Behrman and Deolalikar (1987) contend that, operationally, the choice of one method over another may make a difference. They argue that "the expenditure system (indirect) approach at the level of aggregation at which it is typically applied tends to result in higher estimates of nutrient elasticities with respect to expenditure than the direct estimates, and that the direct estimates probably lead to better, though still possibly upwardly biased, estimates". Their argument is based on the issue of quality. The food good that is used in the food expenditure item is often not a homogeneous commodity. Rather, it is a composite commodity that comprises several items of the same category of food. For instance, the food group "meat" may include not only different kinds of meats such as beef and poultry but may also consist of different qualities of beef. It may include different kinds such as ground beef and filet mignon. As households get richer, they would substitute away from the lower quality cuts toward the more tasty and tender varieties. Not properly taking this into account would tend to overstate the derived calories expenditure elasticity. The fact that richer households choose better quality food items of a given category/group would bias upward the calorie-expenditure elasticity.

The difference between the two estimation procedures is in the degree of neglect of the income elasticity of the average cost of calories of within food groups. In practice, most expenditure-based studies utilise a relatively high level of aggregation of foods. For instance, Pitt (1983) uses 9 food groups. In contrast, studies that directly estimate nutrient demand typically use nutrient data that are calculated from the consumption of a much larger number of detailed food groups, sometimes including different varieties of the same food. Thus, Behrman and Deolalikar (1987) claim that, because the indirect method applies the calorie 
conversion factors at a high degree of aggregation, "the fixed food-nutrient conversion factors used by the expenditure-system-based studies are much less sensitive to intra-food-group substitution of higher-nutrient-cost foods for lowernutrient-costs foods with increased total expenditure”. In other words, the higher the level of aggregation of the commodities, the greater is the second right-hand side term of Equation (5).

To complement their analytical point, Behrman and Deolalikar use a data set from rural India, the ICRISAT data set, and estimate the elasticities according to the two methods. The results obtained from using the indirect method suggest a nutrientexpenditure elasticity close to one (ranging from 0.77 to 1.18 ). However, the second procedure yields estimates that are smaller and not significant at the 5 percent level, with a range from 0.17 to 0.37 . They argue that the critical factor explaining the divergence of the results is the level of aggregation at which the nutrient/food conversion factors are applied. They conclude that "the World Bank-type optimism about the nutrient improvements to be expected with income in [very poor] communities... seems fundamentally misleading”.

\subsection{Calculating the Calorie-expenditure Elasticity Using the Indirect Method}

Let us now estimate the calorie-expenditure elasticity for rural and urban households in Pakistan in 1984-85, taking into account the various estimation concerns mentioned above. The first estimation procedure is to indirectly measure the calorie-expenditure elasticity by using the quantity-expenditure elasticities of the commodities under study. ${ }^{9}$ First, let us compute the calorie-expenditure elasticity without accounting for the quality effect. Furthermore, since one is interested in determining not only the calorie-expenditure elasticity for the full sample but also whether it varies across expenditure levels, the estimation procedure should be done separately for different expenditure levels. As a preliminary step, I chose an arbitrary division of the sample at the fourth decile. Thus, the estimation will be done for the first 4 deciles and will then be performed using the last 6 deciles.

Using the HIES 84-85, Deaton and Grimard (1992) estimate an Almost Ideal Demand System with the methodology of Deaton $(1988,1990)$ to obtain elasticities that can help formulate tax reform policies. This paper applies the same method in order to derive the quantity-expenditure elasticities for the following food categories: wheat products, rice, dairy products, edible oils, sugar, meats, and other foods. The expenditure elasticities were computed for the first four deciles and the last six

${ }^{9}$ All the regressions performed in this paper include province and quarterly dummies to account for differences across space as well as possible seasonal factors that are not captured by the regressors. 
deciles of the rural, urban, and full data set and are shown in Table 5. In general, the elasticities obtained using data from the lowest four deciles of the expenditure distribution are greater than those obtained for the highest six deciles. The special case is edible oils, a basic commodity whose price is controlled by the government. The calorie shares corresponding to these commodities are shown in Table 6. With these two elements, one can apply the indirect method and the first right-hand side term of Equation (5) can easily be found. Table 7 presents the different calories expenditure elasticities for the different deciles.

One sees that the calorie-expenditure elasticity for both urban and rural samples is relatively high (around 0.5) as compared to the Behrman and Deolalikar results. In addition, the elasticity estimates of the rural sector suggest some type of non-linearity: the expenditure elasticity for the first four deciles is 0.67 and the one for the last six deciles is 0.50 . This type of non-linearity does not appear in the urban sector using this method. Of course, without calculating standard errors for the indirect method, one cannot say for certain whether the rural elasticity is different across deciles; but Table 7, nevertheless, points to a possible difference between the poorer and the richer households.

Table 5

\section{Expenditure Quantity Elasticities}

\begin{tabular}{|c|c|c|c|c|c|c|}
\hline & \multicolumn{3}{|c|}{ Rural } & \multicolumn{3}{|c|}{ Urban } \\
\hline & $\begin{array}{c}\text { First } 4 \\
\text { Deciles } \\
\end{array}$ & $\begin{array}{c}\text { Last } 6 \\
\text { Deciles } \\
\end{array}$ & $\begin{array}{c}\text { Full } \\
\text { Sample }\end{array}$ & $\begin{array}{c}\text { First } 4 \\
\text { Deciles } \\
\end{array}$ & $\begin{array}{c}\text { Last } 6 \\
\text { Deciles }\end{array}$ & $\begin{array}{c}\text { Full } \\
\text { Sample }\end{array}$ \\
\hline Wheat & 0.532 & 0.378 & 0.374 & 0.474 & 0.367 & 0.388 \\
\hline Rice & 0.822 & 0.608 & 0.684 & 0.884 & 0.595 & 0.711 \\
\hline Dairy & 1.612 & 0.775 & 1.053 & 1.227 & 0.902 & 1.001 \\
\hline Meats & 1.188 & 0.981 & 1.095 & 1.061 & 0.885 & 0.938 \\
\hline Edible Oils & 0.455 & 0.473 & 0.417 & -0.081 & 0.459 & 0.470 \\
\hline Sugar & 1.023 & 0.811 & 0.865 & 0.789 & 0.551 & 0.648 \\
\hline Other Foods & 0.654 & 0.582 & 0.593 & 0.680 & 0.553 & 0.580 \\
\hline
\end{tabular}

Table 6

Calories Shares

\begin{tabular}{lccccccc}
\hline & \multicolumn{3}{c}{ Rural } & & \multicolumn{3}{c}{ Urban } \\
\cline { 2 - 3 } & First 4 & Last 6 & Full & & First 4 & Last 6 & Full \\
Deciles & Deciles & Sample & & Deciles & Deciles & Sample \\
\hline Wheat & 0.60 & 0.56 & 0.58 & 0.57 & 0.52 & 0.53 \\
Rice & 0.07 & 0.08 & 0.07 & 0.06 & 0.07 & 0.07 \\
Dairy & 0.08 & 0.12 & 0.10 & 0.06 & 0.08 & 0.07 \\
Meats & 0.01 & 0.01 & 0.01 & 0.02 & 0.03 & 0.03 \\
Edible Oils & 0.09 & 0.07 & 0.08 & 0.12 & 0.13 & 0.13 \\
Sugar & 0.04 & 0.05 & 0.04 & 0.06 & 0.07 & 0.07 \\
Other Foods & 0.11 & 0.10 & 0.11 & 0.11 & 0.10 & 0.10 \\
\hline
\end{tabular}


Table 7

Expenditure Calories Elasticities Using the Indirect Method

\begin{tabular}{lccc}
\hline & $\begin{array}{c}\text { First 4 Expenditure } \\
\text { Deciles }\end{array}$ & $\begin{array}{c}\text { Last 6 Expenditure } \\
\text { Deciles }\end{array}$ & Full Sample \\
\hline Rural Sector & 0.674 & 0.500 & 0.526 \\
Urban Sector & 0.531 & 0.479 & 0.515 \\
\hline
\end{tabular}

\subsubsection{Correcting for Quality in the Indirect Method}

The indirect method does not take into account the fact that the average cost of nutrient may vary with income when households seek tastier and more elaborate varieties within the same commodity group. The degree of aggregation of the groups is relatively high and some substitution within each group as households become richer should be expected. One possible way to determine the income elasticity of the average cost of calories is to construct a calorie unit value for each category of goods; i.e., take the expenditure for each category under consideration and divide it by the total number of calories provided by that category. The same methodology used by Deaton $(1988,1990)$ to extract the price and quality effects out of a quantity unit value can then be used to estimate the nutrient cost-income elasticity, which is in fact none other than a version of the Prais-Houthakker quality elasticity. Express the calorie unit value as

$$
\ln v_{G i c}=\alpha_{G}+\beta_{G} \ln x_{i c}+\gamma_{G} \cdot z_{i c}+\sum_{H=1}^{N} \psi_{G H} \ln p_{H c}+\mu_{G i c} \ldots \quad \ldots
$$

where $v$ represents the calorie unit value, $G$ the good category, $c$ the cluster, $i$ the household, $z$ a set of household characteristics and location dummies, $x$ is the total household expenditure, and $p$ the prices of the $N$ categories of goods considered. Assume further that prices do not vary within a cluster. Consequently, one can consistently estimate the Equation by allowing for cluster fixed effects. It is straightforward to compute the mean of the variables for each cluster and run a regression using the deviations from the cluster means of all variables, thereby finding a consistent estimate for $\beta$, the total outlay elasticity of the average cost of nutrient. Doing this estimation for each good gives a crude estimate of the bias introduce by the neglect of this elasticity in the computation of the calorie outlay elasticity.

Table 8 shows the calorie cost expenditure elasticities for the full urban and rural samples. Edible oils and sugar are relatively uniform group commodities with little quality differences within each group. Consequently, the very low and mostly insignificant elasticities for these commodities should not come as a surprise. Wheat, 
rice, and in particular dairy products are commodities where within-group quality differences exist. Indeed, the elasticities are around 0.10 for wheat and rice and are significantly different from zero. ${ }^{10}$ The fact that the average cost of dairy products calories goes down as expenditure rises may be somewhat strange since in the rural sample, at least, the budget and calorie shares increase with expenditure. This may be caused by the construction of the variable. A bulk purchase by low-income households may not be properly recognised. ${ }^{11}$ Note however, that there is no theoretical requirement that each $\eta_{q_{i} E}$ be positive. It is plausible that a commodity group has a negative calorie cost expenditure elasticity. Furthermore, if most groups had negative elasticities, then the bias in neglecting the second term of Equation (5) would actually be downward. This, nevertheless, is an unlikely possibility in our case.

Table 8

Income Elasticities of Average Calorie Cost for Full Samples

\begin{tabular}{lcc}
\hline & Urban & Rural \\
\hline Wheat & 0.045 & 0.105 \\
& $(0.003)$ & $(0.006)$ \\
Rice & 0.111 & 0.107 \\
& $(0.006)$ & $(0.008)$ \\
Dairy & -0.134 & -0.038 \\
& $(0.013)$ & $(0.015)$ \\
Meats & 0.35 & 0.28 \\
& $(0.01)$ & $(0.01)$ \\
Edible Oils & 0.001 & 0.001 \\
& $(0.001)$ & $(0.001)$ \\
Sugar & -0.000 & 0.006 \\
& $(0.001)$ & $(0.001)$ \\
Other Foods & 0.104 & 0.065 \\
& $(0.005)$ & $(0.005)$ \\
\hline
\end{tabular}

Note: Standard errors are in parentheses.

${ }^{10}$ These numbers are somewhat low compared to the ones found in Alderman (1986). One possible reason is that the calories for each group were computed by converting quantities into calories at the lowest level possible given the HIES survey. For instance, calories from milk, butter, and cream were individually created and then added to create a value for calories for dairy products. The quality effect would be stronger if quantities of milk, butter, and cream would have been added and then converted into calories with a given factor.

${ }^{11}$ For instance, if dried milk (an expensive item per unit of quantity, e.g., kg., but likely to be cheap in terms of price per litre, once the powder has been mixed with water) is bought only by lowincome households, then the average cost of dairy products may be high, though as richer households switch to better quality milk and other dairy products, the average cost may decline. 
The second term of Equation (5) can then be computed, thereby resulting in a more realistic estimate of the calorie-expenditure elasticity, as shown in Table 9. For the rural sector, the calorie cost elasticity is 0.072 , yielding a corrected calorieexpenditure elasticity of 0.453 , whereas the urban cost elasticity is only 0.033 , giving a corrected calorie-expenditure elasticity of 0.482 . Thus the upward biases of the indirect method appear to be somewhat important in the overall sample: 16 percent and 6 percent higher in the rural and urban cases. However, these hardly bring down the calorie-expenditure elasticities to zero. If the sample is split at the fourth expenditure decile and the correction is applied to the different elasticities, the biases are again still existent but of a relatively small magnitude.

Table 9

Modified Expenditure/Calorie Elasticities Using the Indirect Method

\begin{tabular}{llccc}
\hline & \multicolumn{1}{c}{ Sample } & $\begin{array}{c}\text { Usual Indirect } \\
\text { Elasticity }\end{array}$ & $\begin{array}{c}\text { Average } \\
\text { Nutrient Cost } \\
\text { Elasticity }\end{array}$ & $\begin{array}{c}\text { Quality } \\
\text { Corrected } \\
\text { Elasticity }\end{array}$ \\
\hline Rural Sector & First 4 Deciles & 0.674 & 0.056 & 0.618 \\
& Last 6 Deciles & 0.500 & 0.054 & 0.446 \\
& Full Sample & 0.526 & 0.072 & 0.453 \\
Urban Sector & First 4 Deciles & 0.531 & 0.034 & 0.497 \\
& Last 6 Deciles & 0.478 & 0.041 & 0.437 \\
& Full Sample & 0.515 & 0.033 & 0.482 \\
\hline
\end{tabular}

Thus, based on an arbitrary split at the fourth expenditure decile, the indirect method estimates suggest that the elasticity is different from zero and that, for the rural sample, it is somewhat higher for the poor than for the rich. These results are essentially similar if we choose to split the sample at a higher decile, say at the sixth or seventh decile, though the difference in elasticities for the rural households is not as large. Rather than repeat the indirect estimation with a different split, we shall present the results of the direct estimation with several possible ways to split the sample.

\subsection{Calculating the Calorie-expenditure Elasticity Using the Direct Method}

The other method to calculate the calorie-expenditure elasticity is to estimate the direct reduced form demand for calories. After having converted quantities of all groups of food consumed into calories using a nutritional table, one then estimates the calorie-expenditure elasticity from a reduced form demand for calories. However, a functional form must be specified and this may bring complications. For instance, Strauss and Thomas (1990) attempt to derive the shape of the calorie-expenditure 
curve using non-parametric and parametric methods for a large cross-section data-set from Brazil. With non-parametric techniques, they find some evidence of a nonlinearity in the calorie-expenditure relationship. Their results suggest that when a certain calorie threshold is reached, households switch to higher protein foods while maintaining an approximately constant level of calorie intake. Consequently, the use of a linear form in a parametric analysis would be inappropriate.

However, while a non-parametric regression frees the researcher from assuming a specific parametric form, this flexibility comes at a price. Indeed, it becomes very difficult to perform non-parametric analysis when the number of covariates increases, for the number of computations increases exponentially with the dimension of the model. Hence, one can only perform a non-parametric regression with 2 independent variables, realistically. This may not be ideal, especially when one wants to take into account household characteristics and regional factors which may be quite influential in determining the consumption of calories in the household. This is why Strauss and Thomas supplement their analysis with a variety of parametric functions. A common functional form in the nutrition literature is a regression of the $\log$ of per capita calorie intake, $\ln N$, on $\log$ of per capita expenditure, In PCE, and, in some cases, a quadratic term in log PCE, including a set of other conditioning covariates, $W$, such as prices or regional dummies, seasonal dummies, and household characteristics.

$$
\ln N=\beta_{0}+\beta_{1} \ln P C E+\beta_{2} \ln P C E^{2}+W \gamma+\epsilon \quad \ldots \quad \ldots
$$

Since the elasticity is a linear function of the log of PCE, this relationship is unlikely to be able to pick up the curvature in the nutrient functions so that elasticities at low expenditure levels may be under-estimated if the true relationship between the elasticity and total expenditure is a decreasing concave function. It is also possible that a quadratic function will force elasticities at high expenditures to be negative. Consequently, Strauss and Thomas also include higher-order polynomials in Equation (7) and propose other parametric forms to reproduce the shape found by their non-parametric analysis. ${ }^{12}$ They estimate several models for per capita calorie and protein intake and find elasticities in the range of 0.25 to 0.30 for calories and 0.40 for protein at the bottom decile of PCE. The problem with these functional forms is that, with the exception of the quadratic polynomial shown in Equation (7), these functions can hardly be derived from any known underlying utility functions. They are only used in order to match the non-parametric shape that Strauss and Thomas have initially found. Consequently, the direct method of estimating

\footnotetext{
${ }^{12}$ For instance, they use a log inverse model and add other terms such as the log of the log of per capita expenditure.
} 
elasticities should restrict itself to functional forms that can be derived from known utility functions. If the data set has a considerable number of observations, then the functional form can be estimated for different percentiles of the expenditure distribution. Hence, even though we do not perform a non-parametric regression, we shall still be able to observe if the relationship between calories and expenditure differs across different segments of the distribution while still accounting for difference in household characteristics and regional variations.

As an initial step in our direct estimation procedure, Table 10 shows the simple regression of the log of total calories on the log of per capita expenditure, family variables, and cluster dummies for the full sample, the poorer and the richer deciles. The estimates from the direct method are indeed lower in magnitude than the estimates from the indirect method, particularly those of the richer deciles. It is interesting to see that once the quality correction has been done on the indirect estimates, the difference between the estimates from the two methods appears to be quite small, particularly for the rural sample. As noted above, the direct method also neglects the within-group substitution factors. The same quality correction method can be applied to correct for within-group quality differences. As shown in Table 9, the quality corrections are rather small.

Table 10

Directly Estimated Calorie Income Elasticities (Simple Functional Form)

\begin{tabular}{lccc}
\hline & First 4 Deciles & Last 6 Deciles & Full Sample \\
\hline Rural & 0.685 & 0.407 & 0.478 \\
Urban & 0.550 & 0.267 & 0.366 \\
\hline
\end{tabular}

Besides the quality factor, the direct estimates also suggest a difference in calorie consumption responses to outlay changes between the poorer and the richer households. Without the guidance of a non-parametric regression, it is hard to determine directly if and where a change in the curvature in the calorie outlay relationship exists. ${ }^{13}$ Two alternative elasticity estimation strategies will be pursued. The first one involves evaluating the linear and non-linear functions suggested by Strauss and Thomas, using a data-set increasing in size: first estimating the functions with data from the poorest five percent of per capita expenditure distribution, then estimating the same functions for the ten percent poorest, and repeating it until the entire data-set is included in the sample. The second option is to divide the full dataset in, say, PCE quintiles and estimate the elasticity for each individual quintile and observe if it varies across quintiles.

${ }^{13} \mathrm{~A}$ quick approach is to regress the $\log$ of per capita calories against the set of household variables, the province and quarterly dummies, and keep these residuals. These residuals are then locally plotted against the log of per capita expenditure using the smoothing LOWESS method described in Cleveland (1979). The graph is shown in Appendix A. 
Tables 11 and 12 present the elasticities for the linear and quadratic polynomial models estimated for cumulative increasing percentiles of the distribution of per capita expenditure. All the models have been estimated with provincial and seasonal dummies as well as with family ratios to account for household composition. Each model's column is followed by another column which examines the same model by using a robust regression method described in Rousseeuw and Leroy (1987) in order to have some rough idea of the sensitivity of the parameters to possible outliers. The method assigns declining weights to extreme residuals and then re-estimates the model. Of course, this procedure is not ideal since it might remove the effects of some true small values that may exist in the data, and consequently the results from these columns should only be treated as an indication of the possible results that could be obtained with a careful analysis of the observations.

Both tables reveal that for every model, the calorie income elasticity declines as the sample becomes larger and richer, supporting the notion that the poorer households may react more to changes in expenditure than the rest of the sample. Also, although most model offer different elasticity estimates for the first deciles, they tend to give a similar estimate for each sample: around 0.46 for the rural and around 0.30 for the urban, which may be considered somewhat high by Behrman and Deolalikar's standards. ${ }^{14}$

Table 11

Expenditure Elasticities of Calories Demand, Urban Sector

\begin{tabular}{|c|c|c|c|c|c|c|c|c|}
\hline \multirow[b]{2}{*}{$\begin{array}{l}\text { Cumu- } \\
\text { lative } \\
\% \text { iles } \\
\text { of PCE }\end{array}$} & \multicolumn{4}{|c|}{ Without Cluster Dummy } & \multicolumn{4}{|c|}{ With Cluster Dummy } \\
\hline & Lnpce & $\begin{array}{l}\text { Lnpce } \\
\text { (Robust) }\end{array}$ & $\begin{array}{l}\text { Quadratic } \\
\text { Polynomial }\end{array}$ & $\begin{array}{l}\text { Quadratic } \\
\text { Polynomial } \\
\text { (Robust) }\end{array}$ & Lnpce & $\begin{array}{l}\text { Lnpce } \\
\text { (Robust) }\end{array}$ & $\begin{array}{l}\text { Quadratic } \\
\text { Polynomial }\end{array}$ & $\begin{array}{c}\text { Quadratic } \\
\text { Polynomial } \\
\text { (Robust) }\end{array}$ \\
\hline 05 & 0.71 & 0.46 & 0.56 & 0.41 & 0.55 & 0.58 & 0.48 & 0.55 \\
\hline 10 & 0.63 & 0.43 & 0.50 & 0.38 & 0.65 & 0.48 & 0.56 & 0.45 \\
\hline 25 & 0.55 & 0.46 & 0.48 & 0.43 & 0.55 & 0.48 & 0.48 & 0.44 \\
\hline 50 & 0.45 & 0.40 & 0.40 & 0.38 & 0.53 & 0.47 & 0.50 & 0.45 \\
\hline 75 & 0.38 & 0.37 & 0.35 & 0.35 & 0.48 & 0.44 & 0.46 & 0.43 \\
\hline 90 & 0.34 & 0.34 & 0.33 & 0.34 & 0.45 & 0.44 & 0.45 & 0.43 \\
\hline 95 & 0.30 & 0.32 & 0.31 & 0.33 & 0.42 & 0.42 & 0.42 & 0.42 \\
\hline 100 & 0.31 & 0.32 & 0.31 & 0.32 & 0.37 & 0.40 & 0.41 & 0.41 \\
\hline
\end{tabular}

Note: The elasticities are evaluated at the sample mean for the given percentile. 'Robust' refers to an iterative regression method described in Rousseeuw and Leroy (1987). It first performs a regression, then calculates weights based on absolute residuals. Large residuals are assigned smaller weights to reduce their influence in the overall regression.

${ }^{14}$ Behrman and Deolalikar (1987)'s preferred estimate is 0.37 with a standard error of 0.37 . Though their estimate is not statistically significant, it does falls between the range of estimates found in this paper. 
Table 12

Expenditure Elasticities of Calories Demand, Rural Sector

\begin{tabular}{|c|c|c|c|c|c|c|c|c|}
\hline \multirow[b]{2}{*}{$\begin{array}{l}\text { Cumu- } \\
\text { lative } \\
\% \text { iles } \\
\text { of PCE }\end{array}$} & \multicolumn{4}{|c|}{ Without Cluster Dummy } & \multicolumn{4}{|c|}{ With Cluster Dummy } \\
\hline & Lnpce & $\begin{array}{c}\text { Lnpce } \\
\text { (Robust) }\end{array}$ & $\begin{array}{l}\text { Quadratic } \\
\text { Polynomial }\end{array}$ & $\begin{array}{l}\text { Quadratic } \\
\text { Polynomial } \\
\text { (Robust) }\end{array}$ & Lnpce & $\begin{array}{l}\text { Lnpce } \\
\text { (Robust) }\end{array}$ & $\begin{array}{l}\text { Quadratic } \\
\text { Polynomial }\end{array}$ & $\begin{array}{c}\text { Quadratic } \\
\text { Polynomial } \\
\text { (Robust) }\end{array}$ \\
\hline 05 & 1.07 & 0.70 & 0.89 & 0.68 & 0.69 & 0.75 & 1.07 & 0.78 \\
\hline 10 & 0.89 & 0.60 & 0.70 & 0.55 & 0.69 & 0.65 & 0.86 & 0.65 \\
\hline 25 & 0.71 & 0.56 & 0.58 & 0.52 & 0.73 & 0.59 & 0.66 & 0.56 \\
\hline 50 & 0.60 & 0.52 & 0.52 & 0.49 & 0.66 & 0.58 & 0.59 & 0.58 \\
\hline 75 & 0.55 & 0.51 & 0.51 & 0.50 & 0.60 & 0.55 & 0.56 & 0.55 \\
\hline 90 & 0.51 & 0.48 & 0.49 & 0.47 & 0.55 & 0.52 & 0.52 & 0.51 \\
\hline 95 & 0.50 & 0.47 & 0.49 & 0.47 & 0.53 & 0.51 & 0.52 & 0.50 \\
\hline 100 & 0.50 & 0.47 & 0.49 & 0.46 & 0.48 & 0.47 & 0.51 & 0.49 \\
\hline
\end{tabular}

As pointed out by Behrman and Wolfe (1984), these estimates may suffer from omitted variable bias. In their analysis, Behrman and Wolfe found that when the education level of the household members was accounted for, the elasticity estimates were reduced. Unfortunately, such information is not available in the HIES data-set and, furthermore, the data-set is only a cross-section. Consequently, one can only correct for missing variables at the cluster level. All the models were estimated with a cluster dummy and the results are shown in the second part of Tables 11 and 12. Instead of diminishing the relatively high elasticity, adding the cluster fixed effect maintains (not increases) somewhat the estimates for most deciles and most models in both samples. This is surprising, since belonging to a cluster with general conditions affecting its households (be it income conditions, ecological conditions, opportunity sets of goods) might help explain a relatively high calorie-income elasticity.

The other interesting fact is that for all models, the elasticity decreases with per capita expenditure deciles, which indicates non-linearity. Furthermore, the estimates performed with the robust regression routines suggest a declining elasticity. The estimations suggest a similar shape of the calorie-expenditure curve when using the parameters obtained for the full sample: a concave curve that gradually becomes flatter as per capita expenditure rises (though not totally flat). Taken for each decile, however, this may be different: the first percentiles (5 percent, 10 percent, 25 percent) have more extreme values which may or may not be legitimate. This can also be seen by comparing the elasticities found using a given model, and the same model can be estimated using the robust regression routine: for the low deciles, there is a large difference between the two values (the routine diminished the importance 
of the "outliers" but as the sample gets closer to the 100 percent percentile, the elasticities obtained by the two methods are almost the same: a sign that the outliers effects are overwhelmed by the rest of the observations). The point, however, is that even when crudely accounting for outliers, the elasticities still decrease as deciles increase. For each decile, the elasticities are similar (except for the lower ones) and the elasticities for the full sample are indeed almost the same and in the neighbourhood of the ones found using the modified indirect method, particularly for the rural sample.

Instead of observing the cumulative percentiles of PCE, dividing the PCE distribution into a finer grid than the one used for Table 10 might suggest sections of the PCE distribution which reveal a greater calorie sensitivity. Table 13 presents the direct calorie-expenditure elasticities computed by using a simple log linear model for each different quintile of the PCE distribution. ${ }^{15}$ For the urban sample, the elasticity appears to stay at the level of 0.50 for the first 4 quintiles and then drops noticeably for the last quintile to around 0.20. As for the rural elasticity, the noticeable drop occurs after the third quintile. Even at the fifth quintile, the elasticities are greater than zero.

\section{CONCLUSION}

The primary theme underlying this paper is the extent to which nutrition will respond to an increase in income. This paper has tried to measure the calories elasticity by attempting to deal with some of the criticisms that recent econometric studies have mentioned. First, the quality issue that Behrman and Deolalikar (1987) pointed out as a major culprit of upward bias has been dealt with and it is found that the bias is not very large (around 0.10 ). Second, the question of omitted variable bias at the cluster level is handled by using fixed-effect estimation. With the help of these two methods, the elasticity is found to be not only different from zero but also higher for the poorer households as compared to the average households. These results, as of those of Alderman (1986) and Deaton and Subramanian (1994), are close to the view that was widely held before the revisionist papers of Behrman and Deolalikar (1987) and Bouis and Haddad (1992), who suggested that the elasticity was near zero.

Nevertheless, there are several reasons why the elasticities estimated in this paper may still be biased upward. First, because of data constraints, the regressions do not include the education level of household members and the household fixed effects cannot be estimated. The estimates may be lower if these corrections are done but one may question: By how much? First, introducing a cluster effect does not

${ }^{15}$ Higher order models were computed but offered insignificant regression parameters for both samples. 
reduce the elasticity and, as Alderman (1993) reports, the inclusion of household fixed effects in most studies did not alter the elasticity estimates. Furthermore, given that education levels are probably higher in the upper quintiles of the income distribution, one may think that the upward bias is greater when one uses the full sample rather than when estimating using different quintiles. In other words, the bias in neglecting education levels may not be large for the lower part of the distribution. This paper's results suggest that the elasticity is higher for the poorer households, so that the upward bias due to a missing variable correlated with income may not be very large.

Second, this paper does not deal with the measurement error issue brought up by Bouis and Haddad (1992). Total household expenditure is the sum of food expenditure and non-food expenditure, each of which is measured with some error. Food expenditure is the sum of a large number of components-the same components which, if appropriately scaled, make up the estimate of total calorie availability. Total expenditure is, therefore, measured with error and the error of measurement is positively correlated with the composite error term in the regression, partly determined by the measurement error in calories. Thus, there is a combination of the standard attenuation bias from the measurement error in total expenditure and the upward bias due to the correlation in the errors of the independent and dependent variables. Examining the linear model, Bouis and Haddad argue that the upward bias outweighs the downward bias. One way to handle this problem is to instrument for total expenditure. Unfortunately, the present data-set does not yield a valid instrument. For the sake of argument, however, assume that the measurement error yields an upward bias that is half of the true value. ${ }^{16}$ Then, the corresponding values for the different quintiles for the rural sector in Table 13 would range from 0.4 to 0.2 . Of course, without the standard errors of the IV estimates, one cannot say anything about whether the estimates would be different from zero. Yet, given the standard errors of Table 13, one would need quite a large decrease in efficiency when using the IV estimator so as to have the elasticity estimate not significantly different from zero. Hence, although it is reasonable to think that the estimate would be reduced if the common measurement error was properly dealt with, it may be difficult to argue that it will bring it down to zero.

Third, one should also recognise that these elasticities are computed from nutritional data from consumption surveys, which typically yield estimates higher than those from direct recall data where interviewers observe, measure, and weigh the consumption of household members. Besides the common measurement error, Bouis and Haddad attribute this phenomenon to the meals provided to servants and workers

\footnotetext{
${ }^{16}$ This proportion is in fact much higher than the one Deaton and Subramanian (1994) find when they estimate an IV regression with non-food expenses as an instrument for total expenditures. They obtain 20 percent of the initial value.
} 
Table 13

Direct Calorie-expenditure Elasticities by Quintiles

\begin{tabular}{|c|c|c|c|c|}
\hline \multirow[b]{2}{*}{ Quintile } & \multicolumn{2}{|c|}{ Urban Sector } & \multicolumn{2}{|c|}{ Rural Sector } \\
\hline & Lnpce & Lnpce (Robust) & Lnpce & Lnpce (Robust) \\
\hline \multirow[t]{2}{*}{1} & 0.575 & 0.510 & 0.778 & 0.621 \\
\hline & $(0.027)$ & $(0.020)$ & $(0.026)$ & $(0.019)$ \\
\hline \multirow[t]{2}{*}{2} & 0.619 & 0.547 & 0.579 & 0.574 \\
\hline & $(0.066)$ & $(0.054)$ & $(0.061)$ & $(0.055)$ \\
\hline \multirow[t]{2}{*}{3} & 0.457 & 0.461 & 0.570 & 0.545 \\
\hline & $(0.076)$ & $(0.059)$ & $(0.075)$ & $(0.062)$ \\
\hline \multirow[t]{2}{*}{4} & 0.520 & 0.475 & 0.383 & 0.375 \\
\hline & $(0.072)$ & $(0.045)$ & $(0.060)$ & $(0.056)$ \\
\hline \multirow[t]{2}{*}{5} & 0.176 & 0.252 & 0.389 & 0.345 \\
\hline & $(0.045)$ & $(0.023)$ & $(0.024)$ & $(0.017)$ \\
\hline
\end{tabular}

Note: Standard errors are in parentheses and cluster dummies have been included in the estimation. 'Robust' refers to an iterative regression method described in Rousseeuw and Leroy (1987). It first performs a regression, then calculates weights based on absolute residuals. Large residuals are assigned smaller weights to reduce their influence in the overall regression.

and to wastage of calories due to preparation. Due to the ubiquitous lack of adequate data, this paper does not deal with these problems. However, meals to servants are unlikely to be a large factor for the poorest households and the estimates from both methods show that the elasticities for these households are higher. As for wastage, there is nothing that one can do to handle this problem. As Deaton and Subramanian (1994) point out, however, this is unlikely to be a source of large overestimation of the elasticity. If that were indeed the case, one would have to believe that "as income rise, households buy more food and more calories simply for the pleasure of throwing them away".

The last caveat is obviously the data-set itself. No matter how much care is taken in estimating a relationship, a research will always be limited by the quality of the data-set used. In the case of the HIES 84-85, Tables 3 and 4 have shown a highstandard deviation of per capita consumption for some deciles. I attempted to correct for these possible difficulties with the use of robust regression methods and the use of a very large number of observations in the hope of removing the effect of extremevalues problems. Yet, no law of large numbers can deal with systematic problems in collecting the data and it is possible that the findings of this paper are unduly influenced by the way the HIES was collected.

Despite the caveats, the results in this paper are reasonable. The calorieexpenditure elasticity estimates ( 0.5 to 0.4 ) of this paper are similar to the estimates Deaton and Subramanian (1994) find with a data-set from India, and also to those found by Alderman (1989) with a panel data-set from rural Pakistan. Alderman finds 
elasticities that are within the 0.3 range; is estimates are somewhat lower than those in this paper probably because information on the education level of the household members was available to him. This paper and the two above-mentioned studies find estimates that are closer to the view held before the criticisms brought up by Behrman and Deolalikar (1987) and Bouis and Haddad (1992). This paper, in particular, finds a difference between the elasticity for the poorer households and that of the average households, suggesting a concave shape in the calorie-expenditure relationship. The estimates obtained here are moderate but clearly positive.

The policy implications, consequently, are similar to those of Reutlinger and Selowsky (1976) which heavily influenced the WDR 1981 view on malnutrition. A policy to increase nutritional intake which augments income of the poorest members of the community appears to be warranted. Of course, concentrating on income only may not be enough to reduce malnutrition. Nutritional status depends on a variety of factors, ranging from knowledge about appropriate diets and access to safe drinkingwater to sound natural resource management. Although it is established that the promotion of nutritional well-being depends on several factors, yet the results in this paper suggest, most importantly, that policy-makers cannot afford to overlook income in their bid to tackle hunger and malnutrition. 
Appendix A

\section{Visual Inspection of the Calories-expenditure Relationship}

As opposed to Deaton and Subramanian (1994), this paper does not use nonparametric methods to estimate the calorie-income elasticity. The parametric estimates that this paper finds suggest some sort of concave relationship between calories and total expenditure. This can be checked visually by first regressing the log of per capita calories against the set of household variables, provincial and quarter dummies. The residuals from this regression are then plotted against the log of per capita expenditure. Using the statistical software STATA, one can use the procedure KSM which uses the LOWESS method described in Cleveland (1979). The graph below shows the relationship for the rural data set. For presentation purposes, the graph is performed on a 25 percent random sample of the 9119 rural households. The dots represent the observations and the dark line is the smoothed relationship using the KSM procedure with the LOWESS method. Although one does not have the usual standard errors of a non-parametric regression, yet one can observe a non-linear relationship.

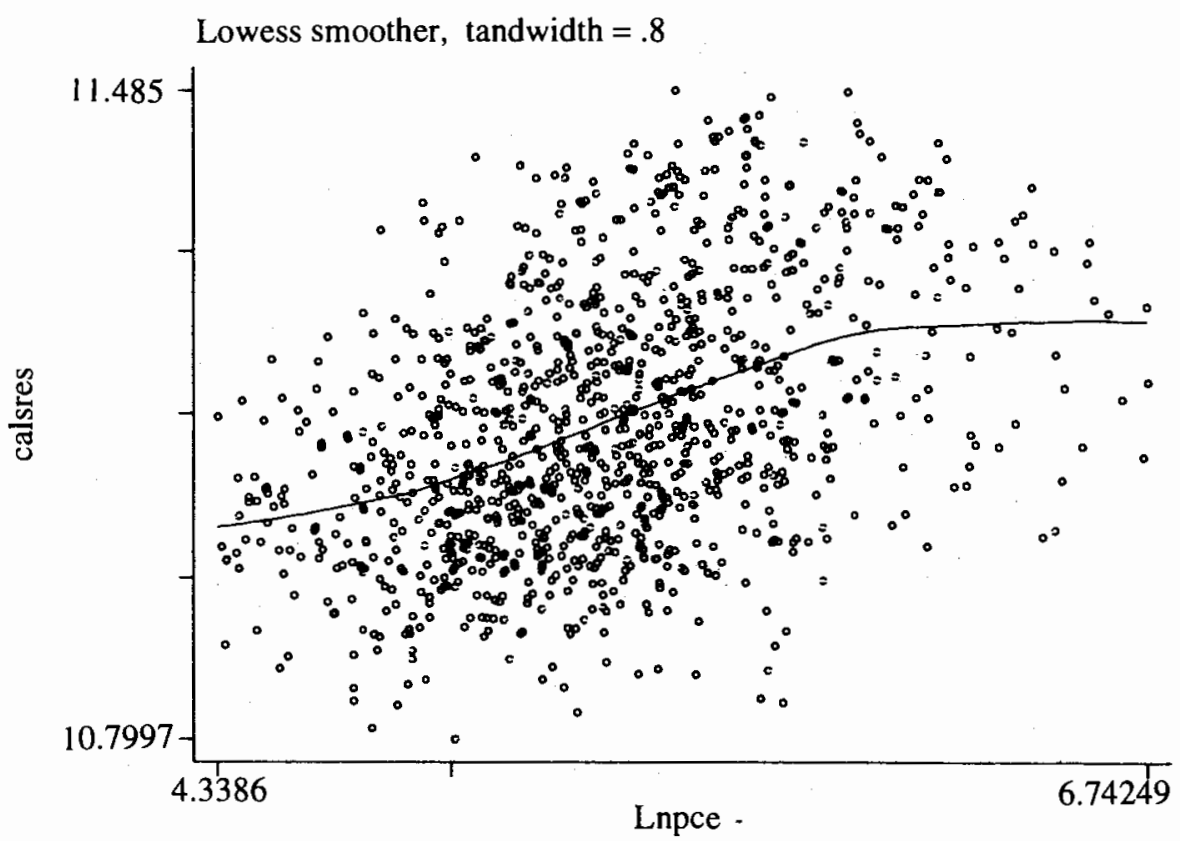




\section{REFERENCES}

Alderman, Harold (1986) The Effect of Food Price and Income Changes on the Acquisition of Food by Low-income Households. Washington, D. C.: International Food Policy Research Institute.

Alderman, Harold (1989) The Impact of Changes in Income and Schooling on the Demand for Food Quantity and Quality in Rural Pakistan. Washington, D. C.: International Food Policy Research Institute.

Alderman, Harold (1993) New Research on Poverty and Malnutrition: What Are the Implications for Policy? In M. Lipton and J. van der Gaag (eds.) Including the Poor. Washington, D. C.: World Bank Regional and Sectoral Studies.

Bouis, Howarth, and Lawrence Haddad (1992) Are Estimates of Calorie-Income Elasticities Too High? A Recalibration of the Plausible Range. Journal of Development Economics 39:2 333-364.

Behrman, Jere R., and Barbara L. Wolfe (1984) More Evidence on Nutrition Demand: Income Seems Overrated and Women's Schooling Underemphasised. Journal of Development Economics 14:1\&2 105-128.

Behrman, Jere R., and Anil Deolalikar (1987) Will Developing Country Nutrition Improve with Income? A Case Study for Rural South India. Journal of Political Economy 95:3 108-138.

Behrman, Jere R., Anil Deolalikar, and Barbara L. Wolfe (1988) Nutrients: Impacts and Determinants. World Bank Economic Review 2:3 299-320.

Cleveland, W. (1979) Robust Locally Weighted Regression and Smoothing Scatterplots. Journal of the American Statistical Association 74:368 829-836.

Deaton, Angus (1988) Quantity, Quality, and Spatial Variation of Price. American Economic Review 78:3 418-430.

Deaton, Angus (1990) Price Elasticities from Survey Data: Extensions and Indonesian Results. Journal of Econometrics 44:3 281-309.

Deaton, Angus, and Franque Grimard (1992) Demand Analysis for Tax Reform in Pakistan. Washington, D. C.: The World Bank. (LSMS Paper No. 85.)

Deaton, Angus, and Shankar Subramanian (1994) The Demand for Food and Calories. Research Programme in Development Studies, Princeton University, (Discussion Paper No. 175.)

Deolalikar, Anil (1988) Nutrition and Labour Productivity in Agriculture: Estimates for South India. The Review of Economics and Statistics 70:3 406-413.

Ercelawn, E. (1990) Absolute Poverty in Pakistan: Poverty Lines, Incidence, Intensity. Karachi: University of Karachi. Applied Economics Research Centre.

Gershoff, Stan, Robert McGundy, Amorn Nundasutin, and Puangton Tantiwongse (1988) Nutritional Studies in Thailand: Effect of Calories, Nutrient Supplements, and Health Interventions on Growth of Pre-school Thai Village Children. American Journal of Clinical Nutrition 48:5 1214-1218. 
Graham, G. G., H. M. Cree, W. C. Maclean, C. H. Kallman, and J. Rabold (1981) Determinants of Growth among Poor Children: Nutrient Intake-Achieved Growth Relationships. American Journal of Clinical Nutrition 34:3 539-554.

Pitt, Mark (1983) Food Preferences and Nutrition in Rural Bangladesh. Review of Economics and Statistics 65:1 105-114.

Reutlinger, Schlomo, and Marcelo Selowsky (1976) Malnutrition and Poverty: Magnitude and Policy Options. Baltimore: Johns Hopkins University Press.

Rousseeuw, P., and A. Leroy (1987) Robust Regression and Outlier Detection. New York: John Wiley \& Sons.

Strauss, John, and Duncan Thomas (1990) The Shape of the Expenditure-Calorie Curve. Yale University. (Economic Growth Center Discussion Paper No. 595.)

Strauss, John (1986) Does Better Nutrition Raise Farm Productivity? Journal of Political Economy 94:2 297-320. 